\title{
Simultaneous production decisions in agricultural contexts: an experimental investigation of pesticide use, animal welfare and wheat production
}

\author{
Julia Höhler \\ Business Economics Group, Wageningen University and Research, \\ Wageningen, The Netherlands and \\ Justus Liebig University Giessen, Giessen, Germany, and \\ Jörg Müller \\ Justus Liebig University Giessen, Giessen, Germany
}

\begin{abstract}
Purpose - Farmers often decide simultaneously on crop production or input use without knowing other farmers' decisions. Anticipating the behavior of other farmers can increase financial performance. This paper investigates the role of other famers' behaviors and other contextual factors in farmers' simultaneous production decisions.

Design/methodology/approach - Market entry games are a common method for investigating simultaneous production decisions. However, so far they have been conducted with abstract tasks and by untrained subjects. The authors extend market entry games by using three real contexts: pesticide use, animal welfare and wheat production, in an incentivized framed field experiment with 323 German farmers.

Findings - The authors find that farmers take different decisions under identical incentive structures for the three contexts. While context plays a major role in their decisions, their expectations about the behavior of other farmers have little influence on their decision.

Originality/value - The paper offers new insights into the decision-making behavior of farmers. A better understanding of how farmers anticipate the behavior of other farmers in their production decisions can improve both the performance of individual farms and the allocational efficiency of agricultural and food markets.
\end{abstract}

Keywords Decision-making, Agriculture, Market entry game, Context effects, Framed field experiment

Paper type Research paper

\section{Introduction}

On-farm production decisions often take the form of what is known as "simultaneous decision-making" in game theory (Nerlove and Bessler, 2001; Savikhin and Sheremeta, 2013). Farmers decide simultaneously what crops to plant and what inputs to use without knowing (most) other farmers' decisions. These simultaneous decisions determine the future supply

\section{JEL Classification — C72, C93, D22, Q13}

(C) Julia Höhler and Jörg Müller. Published by Emerald Publishing Limited. This article is published under the Creative Commons Attribution (CC BY 4.0) licence. Anyone may reproduce, distribute, translate and create derivative works of this article (for both commercial and non-commercial purposes), subject to full attribution to the original publication and authors. The full terms of this licence may be seen at http://creativecommons.org/licences/by/4.0/legalcode

An earlier version of the paper was presented at the 52. Hohenheimer Oberseminar in Weimar. The authors thank the participants of this workshop and especially co-examiner Annika Stöhr for their helpful comments.

Funding: This study received funding by Landwirtschaftliche Rentenbank (Germany).

Simultaneous production decisions 
BFJ

123,13

and thus also the prices. Farmers who are able to anticipate the behavior of other farmers and adapt their own decisions can achieve higher profits (see also Keynes, 1963). Individual production adjustments to (anticipated) future supply are, however, not only crucial for individual farm performance but also for the allocational efficiency of agricultural and food markets (Nerlove and Bessler, 2001). The well-known hog cycle (Harlow, 1960) shows how farmers' myopic expectations can result in serious supply and market price fluctuations. Similar dependencies exist in other areas of agriculture: in crop production, the formation of fungicide resistances and fungicide effectiveness also depend on how (many) neighboring farmers use certain fungicides (Bell et al., 2016).

Previous research has established the role of neighboring farmers' opinions and expectations in production decisions (Borges et al., 2014; Hansson and Ferguson, 2011). Spatial econometric studies have reported spatial spillover effects in farmers' adoption decisions (e.g., Lewis et al., 2011). A number of studies have investigated coordination of production activities in co-operatives (e.g., Alho, 2019; Ollila, 1994). However, much of the previous studies on farmers' decision-making has taken the other farmers' behavior and the resulting states of markets as given (see e.g. Espinosa-Goded et al., 2010 or Kunte et al., 2017). Agent-based models frequently rest on the assumption that farmers do not consider their expectations about other farmers' behavior in their decisions (Happe et al., 2006; Huber et al., 2018). A better understanding of whether and how farmers anticipate the behavior of other farmers in their production decisions can contribute to both the performance of individual farms and the allocational efficiency of agricultural and food markets. A valid measure of decision-making behavior in agriculture is not only relevant from the perspective of production economics and welfare economics, but also for policymaking (Colen et al., 2016; Thoyer and Préget, 2019).

One way to better understand the role of expectations in farmers' decision-making behavior is through economic experiments (Dessart et al., 2019; Thoyer and Préget, 2019). A common experiment to investigate simultaneous decision-making with a large number of agents are market entry games (MEG) (e.g., Camerer and Lovallo, 1999; Erev et al., 2010; Erev and Rapoport, 1998; Rapoport et al., 1998; Seale and Rapoport, 2000). Participants have a binary choice between a fixed payout (not entering the market) and a variable payout (entering the market). The payout on market entry is determined by the market capacity (linear or fixed) and participants' simultaneous decisions on market entry. If the entry rate is lower (higher) than the capacity, the market entry results in higher (lower) payouts than in the event of not entering (e.g., Erev and Rapoport, 1998; Ochs, 1998; Rapoport et al., 1998; Seale and Rapoport, 2000; Zwick and Rapoport, 2002). One major finding - which "looks almost like magic" to Kahneman (1988) - is that the subjects' responses improve in repeated tasks with direct feedback. That is, a convergence to market equilibria can be detected (e.g., Kahneman, 1988; Rapoport, 1995; Rapoport et al., 1998; Sundali et al., 1995). However, the existing MEG fail to resolve the contradiction between experimental markets and real markets. Especially in the case of commodities like oil, metal, milk or grains, market price fluctuations persist (e.g., Ji and Fan, 2012). In part, unpredictable supply shocks like adverse weather conditions and spillover effects such as economic recessions might explain that no equilibrium is reached. Another possible reason for price fluctuations might be that the coordination among market participants is not as perfect as in the experimental setting (Harlow, 1960; Lo, 2005). It is also for these reasons that the external validity of abstract experiments like the MEG has been questioned (Harrison and List, 2004).

The introduction of meaningful contexts can help to increase the external validity of experiments like the MEG. Contexts are believed to increase the understanding of the participants. In addition, they can account for important social considerations of the decision problems that abstract experiments fail to reflect (Alekseev et al., 2017). Through the introduction of context it is also possible to control for the professional experience of the 
subjects (Harrison and List, 2004). Recent evidence suggests farmers' decision-making behavior also depends on the decision-making context (Bell et al., 2016; Menapace et al., 2016; Rommel et al., 2019). Deviations from profit-maximizing behavior, i.e., perfect coordination in MEG, could be a result of suppliers' habitual or attitude-based decisions that results from the field context (Aarts et al., 1998; Harrison and List, 2004; Lo, 2005). Unfortunately, MEG experiments cannot account for this kind of decisions as they consist of decontextualized decision tasks and were conducted with student samples (see also Henrich et al., 2010). Especially when decisions are influenced by behavioral drivers, a contextualized experiment with professionals can contribute to new insights (Herberich et al., 2009; Thoyer and Préget, 2019). The literature lacks contexts for the MEG that make the experiments more realistic and provide insights into field behavior.

The purpose of this study is to explore the relationship between farmers' decision-making behavior, their expectations about other famers, as well as the specific context in which a decision is made. We describe the design and implementation of contextualized MEG to study farmers' production decisions. There are several important areas where this study makes an original contribution to. Firstly, the contribution is methodological in that we apply the MEG to specific contexts. Our contextualized MEG allow players to make decisions based on social considerations, habits and attitudes. Secondly, we contribute to a better understanding of farmers' decision-making and give insights into the underlying reasons for their production decisions. Data for this study were collected using one-shot MEG framed field experiments with 323 German farmers in a between-subjects design. For the analysis, we perform a regression, which explains the observed behavior based on individual assessments on the other actors' behavior as well as self-statements on decision-relevant considerations and characteristics.

In Contexts and hypotheses, we review the relevant literature, present the relevant contexts and develop hypotheses. The experimental design is introduced in Experimental design and data collection. In Results, we present our results. Our paper ends with a discussion and policy implications.

\section{Contexts and hypotheses}

Context often matters for the result of experiments (for an overview, see Alekseev et al., 2017). This has been shown, for example, for ultimatum games (Hoffman et al., 2000), for auctions (Tufano, 2010) as well as for the Prisoner's Dilemma (Liberman et al., 2004), and was discussed for the context of risk attitude (e.g., Zhou and Hey, 2018). For instance, Liberman et al. (2004) show that simply changing the name of the game (Wall Street Game vs. Community Game) results in players behaving differently. Rommel et al. (2019) demonstrate that farmers were willing to take greater risks in an agricultural context. In these experiments "context" regularly refers to the social relations of the actors, which are formulated in the instructions in different ways. A context can help to improve decisions by making them easier to understand and more accessible to participants. Incorporating a meaningful context may increase external validity by affecting both the preferences and the beliefs of the participants (Alekseev et al., 2017). However, there is also a risk that the introduction of contexts will lead to a loss of control over the different effects (Smith, 1976; Levitt and List, 2007). None of the existing context-based experiments examines farmers' decision-making behavior in MEG.

Our examined contexts are simultaneous agricultural production decisions. The decisions are basically structured like the tasks in MEG as described in the introduction. Participants decide between a fixed payout and a variable payout, i.e., between non-market entry and market entry. The amount of the variable payout depends on the market capacity and the decision of all participants. The market capacity refers to the number of firms that can operate the market profitably (see also Sundali et al., 1995). It is expressed as a threshold:

Simultaneous production decisions 
BFJ

123,13

If this threshold is exceeded, the market is considered saturated. It follows that if the entry rate is lower (higher) than the market capacity, the market entry results in higher (lower) payouts than in the event of not entering [1]. In contrast to this neutral context, our simultaneous agricultural production decisions have further contextual aspects in the instructions which might influence managers' decisions: (1) growing wheat with different product qualities, (2) meat production with different process qualities and (3) pesticide use in crop production [2]. In the following, we develop the contexts. The respective instructions can be found in the Table A2 and the supplementary material.

Individual production decisions influence the supply quantity in specific market segments and thus influence prices: Some alternatives like wheat with (very) low product quality and meat with low process quality (conventional husbandry) can be classified as commodities. They can be used in a variety of ways (e.g., wheat for food, feed, and bio-energy production, meat for national and international consumption) and they can easily be substituted. For these products, we assume relatively small price effects caused by supply changes. In our experimental setup they correspond to the non-entry option in MEG. The opposite alternatives - high-quality wheat and meat - are niche products. For example, we assume a relatively small market segment of consumers with willingness to pay for animal welfare (see, e.g. Lagerkvist and Hess, 2010; Höhler and Kühl, 2017). They can be used less versatile and there are no close substitutes. For these products, one might assume relatively large price effects due to local (or national) supply changes. In our experimental setup they correspond to the entry option in MEG. According to this, other farmers' decisions have a relatively small impact on the individual payout of the low-quality options and a relatively high impact on the payout of high-quality products.

The effectiveness of specific fungicide preparations depends, among other things, on whether the pathogens are resistant to the active ingredients they contain. Resistant fungi spread in various ways, e.g., by wind, to the fields of other farmers and cause yield losses. In our experiment, farmers can choose between cheap and expensive preparations. We assume the following simplified context: the inexpensive fungicide contains one active ingredient; the expensive fungicide contains two active ingredients [3]. The inexpensive fungicide carries the threat of resistance formation. We assume that the more farmers use the cheap fungicide, the more likely resistance is to occur. It therefore corresponds to the entry option. The expensive fungicide contains two active ingredients. Resistance formation is therefore less likely. In our experiment, this corresponds to the non-entry option. For simplification, it is assumed that no resistance can develop.

Our hypotheses address underlying reasons for the expected differences between contexts and participants' responses. Real-world decisions might be more complex and producers might not only consider (short-term) payouts but may have subjective attitudes towards certain alternatives. In comparison to a neutral context, we expect a difference in the proportions of market entries:

H1. Real-world context transfers to the experiment: The proportion of market entries varies depending on decision contexts.

We expect the following effects of the contexts: In the wheat context, high-quality and low-quality are equally socially desirable. But in the meat context, conventional husbandry (low quality) is likely to be less socially desired than animal-welfare oriented husbandry (high-quality) (Lusk and Norwood, 2010). Due to this, in the meat context, farmers might have a more positive attitude toward animal-welfare oriented husbandry and, thus, would not base their decisions (only) on payout considerations. In the context of pesticides, the more expensive pesticide is socially desirable as it does not lead to resistance formation. In addition, in the wheat and meat context, farmers could make habitual decisions and choose the alternative they have chosen in recent years instead of making payout considerations. If 
habits are present, the shares of decisions for high and low quality might depend on producers' real-world decisions (see $\mathrm{H} 1$ ).

In the pesticide context, in addition to the short-term impact of resistance formation (yield losses in a given production period), long-term disadvantages may also arise. Currently, only five groups of active ingredients are available to protect cereals against harmful fungi. If a resistance against an active substance group occurs, farmers' decision space is limited in the future. As a result, prices for the remaining active ingredients could rise, so that resistance formation poses a long-term danger of higher production costs. This might lead to two kinds of reasons for negative attitudes toward cheap pesticides, a threat of individual and collective long-term disadvantages caused by fewer alternatives and higher costs.

The second hypothesis addresses the influence of different (market) capacities. We assume that the larger the capacity, the more subjects will choose the alternative with the variable payout (Sundali et al., 1995).

H2. The larger the market capacity, the larger the proportion of market entries.

In addition, we assume that the beliefs (Schotter and Trevino, 2014) about the other participants influence the respondents' own decisions (Erev and Rapoport, 1998).

H3. The higher the anticipated proportion of other participants' market entries, the less likely is a market entry of the participant.

Another reason why participants do not choose to enter the market could be their risk aversion (e.g., Weber et al., 2002; Zwick and Rapoport, 2002).

H4. The more risk-averse a participant is, the more likely (s)he will not enter the market.

To test our hypotheses, we conduct a framed field experiment with professionals and a context known to the participants (real-world tasks). By this mean we are able to observe the behavior of subjects making decisions they are familiar with. This relates to the task itself and the environmental factor in question, namely other producers.

\section{Experimental design and data collection \\ Overview}

In our study, we conduct incentivized one-shot MEG field experiments with eight treatments, varying contexts (4) and different market capacities (2). In addition to the above-mentioned contexts (wheat, meat, and pesticides), we use a neutral task as a control.

Under real-world conditions, farmers can choose between many alternatives [4] and the respective benefits are gradually influenced to a varying degree by the decisions of other farmers. Marginal changes in other farmers' behavior result in marginal changes in payout amount as a result of relatively complex relationships between supply and demand (wheat and meat) or biological processes (pesticide) [5]. In order to avoid overstraining the subjects and to exclude other influencing factors, we have simplified the task in our experiment in two aspects:

(1) The task consists only of the choice between two alternatives (A and B). Alternative A represents the previously described low-quality commodities in the wheat and meat contexts as well as the expensive fungicide in the pesticide example (non-market entry). Conversely, alternative B stands for high-quality commodities and a cheap fungicide (market entry).

(2) The payout on alternative A will not be affected by other participants' decisions. Regardless of how many people choose alternative A, the profit is 40 Euro. The payout on alternative B can have two states and depends on the proportion of
Simultaneous production decisions

\section{e}


$\mathrm{BFJ}$

123,13

\section{4}

subjects choosing alternative $\mathrm{B}$ as well as the market capacity, which is specified by a threshold:

- If the threshold is exceeded, the payout is low $(€ 20)$. This situation represents oversupply of high-quality wheat or meat and the appearance of a resistance to a cheap pesticide.

- If the threshold is not exceeded, the payout is high $(€ 60)$. This situation represents undersupply of high-quality wheat or meat and no resistance formation against a cheap pesticide.

Due to our simplifying assumptions, it is difficult to draw on comparative threshold values from reality. Therefore we perform two treatments for each context, which differ in their thresholds $\left(s_{\mathrm{th}}\right)$. These are $\geq 20 \%$ (treatment $\left.1, s_{\mathrm{th} 1}\right)$ and $\geq 80 \%$ (treatment $2, s_{\text {th } 2}$ ) of participants choosing alternative B. We chose these two values to cover a wide span. $s_{\text {th1 } 1}\left(s_{\text {th2 }}\right)$ represents a market with a low (high) market capacity where a relatively low (high) supply of high-quality products leads to an oversupply. In the case of fungicides, $s_{\text {th } 1}\left(s_{\text {th } 2}\right)$ represents a situation with a relatively high (low) likelihood of resistance formation. The payout amount refers to one production unit and is derived from real values (costs and revenues) [6]. This is supposed to create a higher degree of realism.

\section{Nature and conduct of the survey}

Data collection took place during several practical workshops and an agricultural fair (Agritechnica) in Germany in 2017 and 2018. At the fair, a sign was used to advertise participation. At the workshops, a session was set up in which the experiment was conducted. Each treatment was performed with at least 30 participants in a between-subjects design. The unequal numbers between the treatments are a result of our data collection; depending on the number of farmers present, larger group sizes could be achieved. The assignment was random, apart from the meat treatment. Since not every farmer also produces pigs, we decided to ask in advance whether they keep pigs. This procedure ensured that subjects were confronted with decision contexts they face in reality. This increases the external validity, but is at the expense of the internal validity, since systematic differences between the control group and the meat group cannot be excluded (Roe and Just, 2009). Farmers received the information that 30 farmers were participating in their treatment. We assume that the partially deviating number of participants has no influence on the outcome, because they filled out the questionnaire alone and did not know who was in their treatment. We have proceeded in this way in order not to have to exclude individual farmers in the workshops from participating.

The participation lasted about $10 \mathrm{~min}$. First, the experiment was explained. The participants had time to read and ask questions (see Table A1). Next followed the decision-making task (see Table A2, supplementary material). Afterwards the questionnaire was handed out (see Table A3). Finally, the drawings for monetary rewards were conducted. Twenty percent of the participants were randomly drawn at the end of the experiment and won the sum they had earned by making their selection (for a discussion of different payment approaches, see Charness et al., 2016). The farmers were asked to give a number from 0 to 9 and were provided with a ten-sided dice, which they had to roll twice. If the number previously specified by the participant was thrown, the payment was made. Payment was made shortly afterwards when a treatment was completed. A total of 1,620 Euro was disbursed. 40 participants won, so that on average 40.5 Euro were achieved.

In the questionnaire, the participants were asked to rate how many other participants chose alternative $B$ (in percent). In the case of wheat and meat, we also asked them to indicate their decision in reality with the two alternatives. This was done to control for habitual 
decision making. Participants were asked to indicate their risk attitude on an eight-point scale from 1 (not risk-taking at all) to 8 (very high risk-taking). A similar scale has already been used by Dohmen et al. (2011) and is characterized by its simplicity. A disadvantage may be that the results do not always correlate with actual behavior (Menapace et al., 2016).

Table 1 gives an overview of the experimental setup and the sizes of the subsamples.

\section{Sample}

The sample consists of 323 farmers who regularly face the decisions mimicked in the experiment. The descriptive statistics are shown in the appendix (Table A4). The population consists of 275,400 agricultural holdings. Large companies tend to be slightly overrepresented in our sample (Destatis, 2018a, b).

\section{Results}

The results are presented as follows: first we descriptively compare the selection between alternative $\mathrm{A}$ and $\mathrm{B}$ by context and threshold. We perform statistical tests to investigate differences in the selection by context and threshold. In the next step we present the expectations (beliefs) of the participants. The comparison between selection and beliefs shows which strategies the participants have pursued. Finally, a regression analysis is performed.

Table 2 indicates the selection of alternative $\mathrm{B}$ by context and by threshold in percent. It can be stated that in the treatment with 20 percent the threshold was exceeded in three treatments but not for pesticides. In the treatment with 80 percent, the threshold was never exceeded. A chi-squared test reveals significant differences in the selection of $B$ between the contexts $\left(X^{2}=8.223, p=0.042\right.$ for $s_{\text {th } 1}$ and $X^{2}=8.390, p=0.039$ for $\left.s_{\text {th } 2}\right)$ and between the thresholds $\left(X^{2}=8.212, p=0.004\right)$. The comparison of the effect size $\phi$ reveals that the difference between the contexts $(\phi=0.227)$ is stronger than the difference between the thresholds $\left(\phi=0.159\right.$ for both $\left.s_{\text {th }}\right)$. This is surprising since one would expect the opposite result from rational decision-makers.

In the meat context, alternative B is chosen more frequently than in the neutral context and all other contexts. In contrast, in the pesticide context, alternative B is chosen less frequently compared to the neutral context and to all other contexts.

Table 3 shows the participants' average beliefs regarding the entry rate of the other players.

The average values show similar tendencies as the actual selection. In the pesticide context, the beliefs about the proportion of market entrants tend to be lower. In the meat context, the beliefs about the proportion tend to be higher. If we compare the estimates with the actual selection, we see a mismatch between individual entry rates and participants'

\begin{tabular}{|c|c|c|}
\hline \multirow[b]{2}{*}{ Context } & \multicolumn{2}{|c|}{ Threshold $\left(s_{\mathrm{th}}\right)$} \\
\hline & $s_{\text {th1 }}=20 \%$ & $s_{\text {th2 }}=80 \%$ \\
\hline Neutral (control) & $n=42$ & $n=44$ \\
\hline Wheat & $n=40$ & $n=41$ \\
\hline Meat & $n=34$ & $n=33$ \\
\hline Pesticide & $n=44$ & $n=45$ \\
\hline Total & 160 & 163 \\
\hline
\end{tabular}

Source(s): Authors' data
Simultaneous production decisions

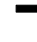

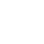


BFJ 123,13

\section{6}

Table 2.

Selection of alternative $\mathrm{B}$ by context and by threshold assessments of the other participants. On the one hand, in the $20 \%$ threshold treatment, alternative $B$ is chosen by some participants even if they think the limit was exceeded. On the other hand, in the $80 \%$ threshold treatment, alternative B was chosen less frequently than the average beliefs suggest.

By asking the participants about their beliefs on the proportion of other participants who chose $\mathrm{B}$, we can classify ex-post whether a profit-maximizing strategy is applied. Those who choose B, even though they believe that the threshold is exceeded, or those who choose A, although they believe that the threshold is not exceeded, are characterized as participants with no ex-post-profit-maximizing strategy. Table 4 shows that the proportion of ex-postnon-profit-maximizing participants varies by context and by threshold. Overall, less than $55 \%$ choose a profit-maximizing strategy.

These contradictory observations give us the opportunity to look more closely at the determinants of the decision in a regression model. We conduct a logit regression and test three different specifications. The market entry (alternative B) is our dependent variable $y$ with two realizations: 0 (no market entry) and 1 (market entry). Table 5 shows our results. In model 1, we test H1-H3 and use categorical variables for the context, a dummy variable for the threshold (1, if threshold is $80 \%, 0$ if it is $20 \%$ ), and the beliefs about the proportion of market entry as independent variables. In model 2, we include the participants' self-stated risk attitude. In model 3, a dummy variable is added to determine whether the test person is applying alternative B in reality. The dummy variable can be viewed as an indicator of habitual behavior and was queried for the contexts meat and wheat. For the context of fungicides it is not purposeful because of the large selection of products in the market.

In model 1 , only the meat context and the beliefs about the entry rate have statistically significant $(\phi<0.05)$ coefficients. With the meat context, the probability of entry increases significantly in comparison to the neutral context (odds ratio $(\mathrm{OR})=2.451$ ). The beliefs about the entry rate have only a weak $(\mathrm{OR}=1.022)$ impact on the decision. The sign is reversed than expected. The higher the beliefs about the collective entry rate, the more likely individual

\begin{tabular}{|c|c|c|c|}
\hline & & Percent & rative $B$ \\
\hline & & $20 \%$ threshold treatment & $80 \%$ threshold treatment \\
\hline Context & Neutral (control) & 26.2 & 40.9 \\
\hline & Wheat & 35.0 & 41.5 \\
\hline & Meat & 44.1 & 66.7 \\
\hline & Pesticide & 15.9 & 35.6 \\
\hline & Total & 29.4 & 44.8 \\
\hline Source & rs' data & & \\
\hline
\end{tabular}

\begin{tabular}{lcccc}
\hline & \multicolumn{2}{c}{ Threshold $=20 \%$} & Beliefs & \multicolumn{2}{c}{ Threshold $=80 \%$} \\
& Mean & Std. Error & Mean & Std. Error \\
\hline Neutral (control) & 40.83 & 2.49 & 53.80 & 3.30 \\
Wheat & 42.35 & 2.60 & 50.22 & 2.76 \\
Meat & 45.24 & 3.83 & 55.64 & 3.60 \\
Pesticide & 36.61 & 3.07 & 48.10 & 3.03 \\
Total & 41.24 & 1.50 & 51.72 & 1.60 \\
Source(s): Authors' data & & & & \\
\end{tabular}


entry will be. This is counterintuitive. $67.7 \%$ of cases can be classified correctly with this model. The signs of the non-significant coefficients are as expected in the hypotheses.

In model 2 we add the risk attitude which increases the explanatory power. The more a participant indicates risk-taking behavior, the more likely (s)he chooses alternative B. In addition, both the context and the market capacity have an impact on the decision. Hypotheses 1, 2 and 4 cannot be rejected. The other coefficients do not change their direction. In comparison to model 1 , model 2 has a higher prediction accuracy.

In Model 3, prediction accuracy can be further improved by including the participant's decision in reality. If a participant has experience with alternative $\mathrm{B}$, the market entry is more likely (OR: 2.659). While the other coefficients remain stable, the sign of the wheat context changes. In this treatment, experience with an alternative seems particularly strong in explaining the decision. Compared to a random prediction, the accuracy can be improved by $22 \%$.

\section{Discussion and policy implications}

We have designed contextualized MEG to explore the relationship between farmers' decisionmaking behavior, their expectations about other farmers, as well as the specific context. The relevance of context in experimental research on farmers' decision-making behavior is clearly supported by the current findings. Context-specific evidence is of critical importance for the effectiveness of policies and programs that aim at providing a stable supply of affordable food and the production of food of certain qualities (e.g., animal welfare-friendly meat). Incentives for environmental and climate action, as planned for the EU's common agricultural policy after 2020 (European Commission, 2020), could also benefit from a context-specific approach. Assuming only profit maximization, in contrast, might result in poor predictions of uptake rates (Colen et al., 2016; Thoyer and Préget, 2019). A better understanding of the behavioral drivers of farmer decision-making can support the design of targeted and effective policy measures (Dessart et al., 2019).

The analysis of strategies (Tables 3 and 4 ) indicates that by no means all participants act profit-maximizing by adapting their behavior to their assessment of the other participants. The participants seem to adapt their decision-making behavior to the context and thus forego monetary payouts in favor of other objectives. These results further support the idea of accounting for the diversity of farmer's objectives when predicting farmers' compliance rates with new regulations (Colen et al., 2016). The results of the regression models show that risk attitude is another key variable in explaining behavior. As one would expect from rational decision-makers, market capacity also plays a role in the decision of the participants. However, comparing the effect sizes showed that contexts are more important overall. In contrast, the beliefs about the behavior of other participants play only a marginal role. Surprisingly, an increase in expected market entry rates even increases the individual entry probability. This finding is contrary to the assumption of rational profit maximization. It could be attributed to what is called "reference group neglect" by Camerer and Lovallo (1999). Their findings suggest that participants are overconfident in their skills and become

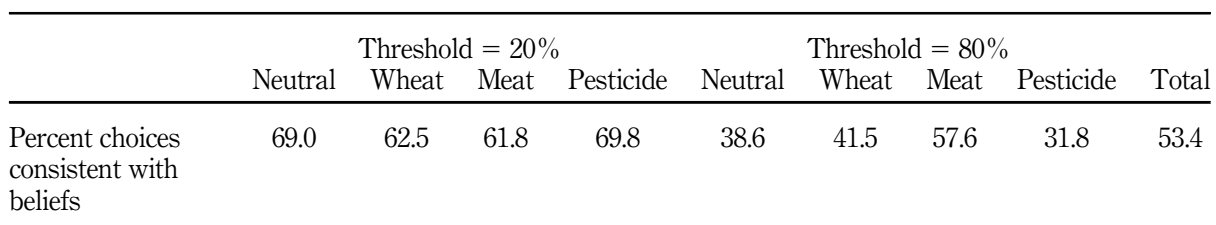

Source(s): Authors' data
Simultaneous production decisions 
BFJ
123,13

\section{8}

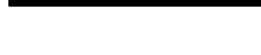

Table 5.

Logit estimation of entry decision

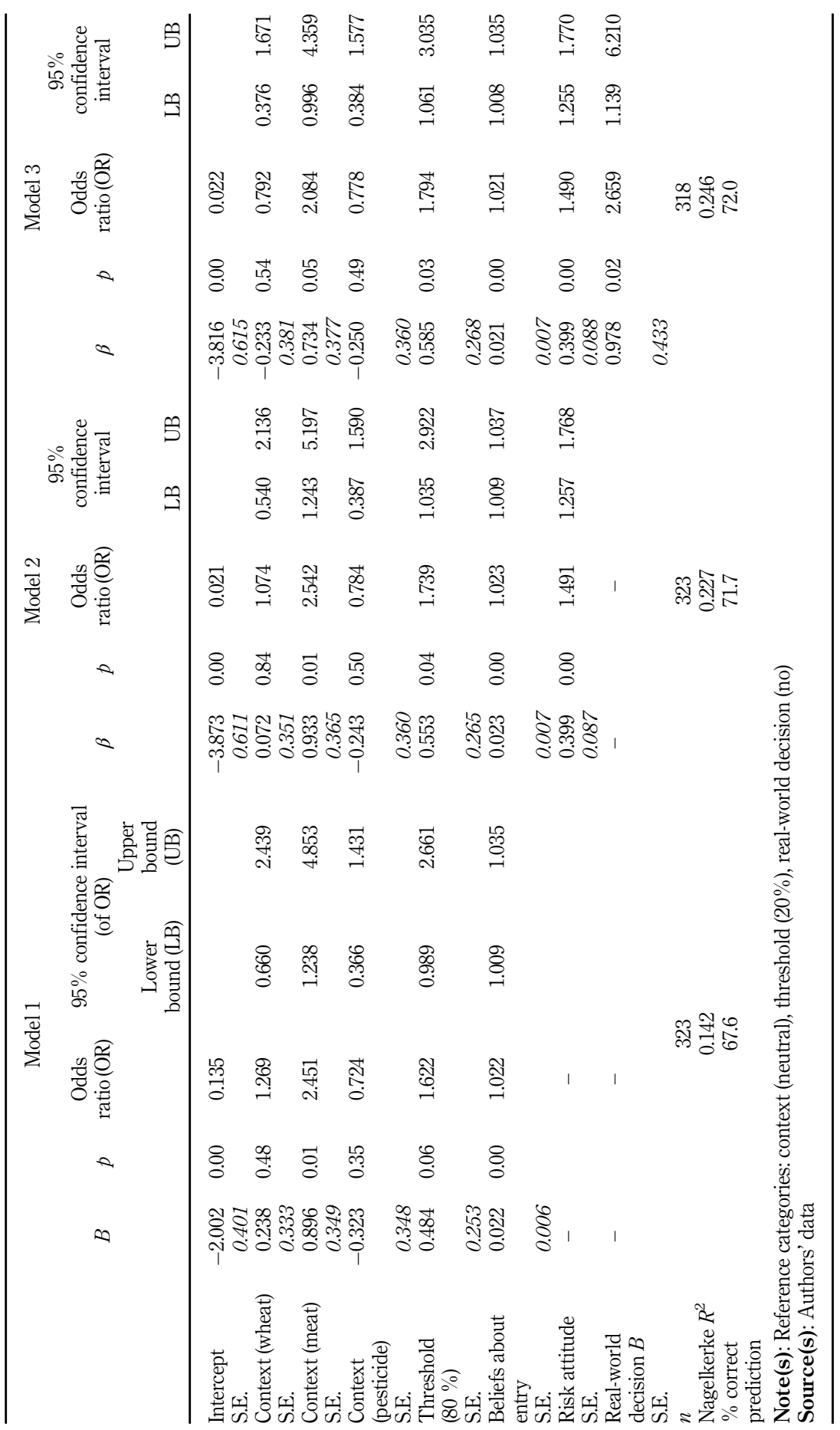


insensitive to their competitors. Another explanation is the underweighting of rare events. Participants enter the market if it leads to higher payouts, even if this decision decreases expected payouts (Erev et al., 2010). Further research should be undertaken to explore how expectations about the decisions of other farmers influence farmers' decision-making behavior.

Comparison of the findings with those of other studies (e.g., Menapace et al., 2016) confirms the role of contexts in economic experiments. Although the choice task was the same across all treatments, context-specific instructions have influenced farmers' decision-making behavior. This results may be explained by the fact that behavioral factors, like habits (see Table 5, model 3), play a previously neglected role in the choice of market strategies. For the meat and the pesticide context, a possible explanation might be that social desirability plays a role. In the pesticide context, long-term considerations could also be relevant. Farmers forego short-term profits in order to avoid the development of resistance and to be able to make profits in the long term. This type of consideration is not reflected in classic MEG. However, it is difficult to distinguish between the exact effects and there is a possibility of them overlapping in the experiment. Further studies, which take these variables into account, will need to be undertaken. The advantage of abstract experiments is that they can be replicated across cultures and regions (Alekseev et al., 2017). However, the impact of the contexts may differ in this respect. Replicating this study in different countries is required to obtain more general results.

Our experiment is a one-shot game. In this way, we avoid measuring learning and coordination effects that would occur as a result of immediate feedback. Other practical considerations speak in favor of a one-shot game: farmers are familiar with the decision, in reality they receive no direct feedback either, and conditions change from year to year. Since the study was limited to one round, it is not possible to examine the occurrence of market equilibria in subsequent rounds. However, simulation models could use our results to investigate the impact of repeated games on the overall market as well as to enrich objective functions (Colen et al., 2016; Thoyer and Préget, 2019).

The study is limited by the lack of complete and comparable information on farm sizes which could have been used as control variables. An additional uncontrolled factor is the possibility of unobserved heterogeneity in our sample. The sample was recruited at a trade fair and workshops. A self-selection of the participants can therefore not be precluded (see also Colen et al., 2016). A random assignment across all contexts and a within-subjects design could have prevented this. We decided against the former because of the internal validity (see above). We refrained from a within-subjects design due to the limited time available to our test persons and to avoid learning effects. A further limitation of this study is that in reality farmers have the opportunity to diversify; this was not possible in the experiment. Repeating the experiment with additional contexts could lend additional support to our findings. In addition, the effect of further thresholds as well as price functions in alternative B should be investigated. By incentivizing belief and risk elicitations (see Rommel et al., 2017) the stability of the previous results could be verified. Notwithstanding these limitations, the study adds to our understanding of the role of contexts in economic experiments. This means that the context of the decision should be given more importance in future experiments. Especially the experience with an alternative in reality can make a significant contribution to the decision in the experiment.

\section{Notes}

1. Hereafter referred to as neutral context.

2. Hereafter referred to as wheat, meat and pesticide, respectively.

3. For a detailed discussion of fungicide-resistance and its determinants, see Van den Bosch et al. (2014).
Simultaneous production decisions 
$\mathrm{BFJ}$ 123,13

4. Examples from Germany: Wheat: Wheat is classified in at least five quality groups according to protein content and falling number: Quality wheat, bread wheat, elite wheat, biscuit wheat and other wheat. Meat: animal-welfare oriented, conventional, regional or organic production. Fungicides: In grain production, five groups of active ingredients are used in 21 preparations with single and 44 preparations with multiple active ingredients.

5. In the examples wheat and meat, market prices of alternatives are the result of relatively complex interactions between supply and demand functions. Marginal supply changes lead to marginal price changes. Fungicide resistances can be qualitative or quantitative. For qualitative resistances, there are two situations: Either there is a complete resistance and the fungicide is completely ineffective, or no resistance occurs and the fungicide is completely effective. Quantitative resistances are partial and a fungicide loses its effect gradually.

6. The calculation of the payout amount is explained in more detail in Table A2 and the supplementary material.

\section{References}

Aarts, H., Verplanken, B. and van Knippenberg, A. (1998), "Predicting behavior from actions in the past: repeated decision making or a matter of habit?", Journal of Applied Social Psychology, Vol. 28 No. 15, pp. 1355-1374.

Alekseev, A., Charness, G. and Gneezy, U. (2017), "Experimental methods: when and why contextual instructions are important", Journal of Economic Behavior and Organization, Vol. 134, pp. 48-59.

Alho, E. (2019), Essays on Investment Behavior in Agricultural Producer Cooperatives, Dissertation, University of Helsinki, Helsinki.

Bell, A., Zhang, W. and Nou, K. (2016), "Pesticide use and cooperative management of natural enemy habitat in a framed field experiment", Agricultural Systems, Vol. 143, pp. 1-13.

Borges, J.A.R., Lansink, A.G.O., Ribeiro, C.M. and Lutke, V. (2014), "Understanding farmers' intention to adopt improved natural grassland using the theory of planned behavior", Livestock Science, Vol. 169, pp. 163-174.

Camerer, C. and Lovallo, D. (1999), "Overconfidence and excess entry: an experimental approach", The American Economic Review, Vol. 89 No. 1, pp. 306-318.

Charness, G., Gneezy, U. and Halladay, B. (2016), "Experimental methods: pay one or pay all", Journal of Economic Behavior and Organization, Vol. 31, pp. 141-150.

Colen, L., Gomez y Paloma, S., Latacz-Lohmann, U., Lefebvre, M., Préget, R. and Thoyer, S. (2016), "Economic experiments as a tool for agricultural policy evaluation: insights from the European CAP”, Canadian Journal of Agricultural Economics/Revue canadienne d'agroeconomie, Vol. 64, pp. 667-694.

Dessart, F.J., Barreiro-Hurlé, J. and van Bavel, R. (2019), "Behavioural factors affecting the adoption of sustainable farming practices: a policy-oriented review", European Review of Agricultural Economics, Vol. 46 No. 3, pp. 417-471.

Destatis (2018a), Agricultural Holdings, Statistisches Bundesamt. available at: https://www.destatis.de/ EN/FactsFigures/EconomicSectors/AgricultureForestryFisheries/AgriculturalHoldings/Tables/ SelectedFeaturesTC.html.

Destatis (2018b), Animals and Animal Production, Statistisches Bundesamt. available at: https://www. destatis.de/EN/FactsFigures/EconomicSectors/AgricultureForestryFisheries/AnimalsAnimalPr oduction/Tables/3HoldingsWithPigsAndStockOfPigs.html.

Dohmen, T., Falk, A., HuffmanSundeSchupp, D.U.J. and Wagner, G.G. (2011), "Individual risk attitudes: measurement, determinants and behavioral consequences", Journal of the European Economic Association, Vol. 9 No. 3, pp. 522-550.

Erev, I. and Rapoport, A. (1998), “Coordination, 'magic', and reinforcement learning in a market entry game”, Games and Economic Behavior, Vol. 23, pp. 146-175. 
Erev, I., Ert, E. and Roth, A.E. (2010), "A choice prediction competition for market entry games: an introduction”, Games, Vol. 1 No. 2, pp. 117-136.

Espinosa-Goded, M., Barreiro-Hurlé, J. and Ruto, E. (2010), "What do farmers want from agri-environmental scheme design? A choice experiment approach", Journal of Agricultural Economics, Vol. 61 No. 2, pp. 259-273.

European Commission (2020), "Future of the common agricultural policy". available at: https://ec. europa.eu/info/food-farming-fisheries/key-policies/common-agricultural-policy/future-cap_ en\#objectives.

Federal Ministry of Food and Agriculture (2020), "Agricultural statistical yearbook (agrarstatistisches jahrbuch)”. available at: https:/www.bmel-statistik.de/fileadmin/SITE_MASTER/content/ Jahrbuch/Agrarstatistisches-Jahrbuch-2019.pdf.

Hansson, H. and Ferguson, R. (2011), "Factors influencing the strategic decision to further develop dairy production - a study of farmers in central Sweden”, Livestock Science, Vol. 135 Nos 2-3, pp. 110-123.

Harlow, A.A. (1960), "The hog cycle and the cobweb theorem", American Journal of Agricultural Economics, Vol. 42 No. 4, pp. 842-853.

Happe, K., Kellermann, K. and Balmann, A. (2006), "Agent-based analysis of agricultural policies: an illustration of the agricultural policy simulator AgriPoliS, its adaptation and behavior", Ecology and Society, Vol. 11, p. 1.

Harrison, G.W. and List, J.A. (2004), "Field experiments", Journal of Economic Literature, Vol. 42 No. 4, pp. 1009-1055.

Henrich, J., Heine, S.J. and Norezayan, A. (2010), “The weirdest people in the world?", Behavioral and Brain Sciences, Vol. 33, pp. 61-135.

Herberich, D., Levitt, S. and List, J. (2009), "Can field experiments return agricultural economics to the glory days?”, American Journal of Agricultural Economics, Vol. 91 No. 5, pp. 1259-1265.

Höhler, J. and Kühl, R. (2017), "Vertical coordination in the meat supply chain - the effects of (unlabeled) private standards for animal welfare", German Journal of Agricultural Economics, Vol. 66 No. 3, pp. 149-158.

Hoffman, E., McCabe, K. and Smith, V. (2000), "The impact of exchange context on the activation of equity in ultimatum games", Experimental Economics, Vol. 3, pp. 5-9.

Huber, R., Bakker, M., Balmann, A., Berger, T., Bithell, M., Brown, C., Grêt-Regamey, A., Xiong, H., Le, Q.B., Mack, G., Meyfroidt, P., Millington, J., Müller, B., Polhill, J.G., Sun, Z., Seidl, R., Troost, C. and Finger, R. (2018), "Representation of decision-making in European agricultural agent-based models", Agricultural Systems, Vol. 167, pp. 143-160.

Ji, Q. and Fan, Y. (2012), "How does oil price volatility affect non-energy commodity markets?", Applied Energy, Vol. 89 No. 1, pp. 273-280.

Kahneman, D. (1988), "Experimental economics: a psychological perspective", in Tietz, R., Albers, W. and Selten, R. (Eds), Bounded Rational Behavior in Experimental Games and Markets, Springer, Berlin, pp. 11-18.

Keynes, J.M. (1936), The General Theory of Employment, Interest and Money, New ed., Cambridge University Press, Cambridge.

Kunte, S., Wollni, M. and Keser, C. (2017), "Making it personal: breach and private ordering in a contract farming experiment", European Review of Agricultural Economics, Vol. 44 No. 1, pp. 121-148.

Lagerkvist, C.J. and Hess, S. (2010), “A meta-analysis of consumer willingness to pay for farm animal welfare”, European Review of Agricultural Economics, Vol. 38 No. 1, pp. 55-78.

Levitt, S.D. and List, J.A. (2007), "What do laboratory experiments measuring social preferences reveal about the real world?”, Journal of Economic Perspectives, Vol. 21 No. 2, pp. 153-174.

Lewis, D.J., Barham, B.L. and Robinson, B. (2011), "Are there spatial spillovers in the adoption of clean technology?”, The Case of Organic Dairy Farming-Land Economics, Vol. 87 No. 2, pp. 250-267.

Simultaneous production decisions 
$\mathrm{BFJ}$ 123,13

Liberman, V., Samuels, S.M. and Ross, L. (2004), "The name of the game: predictive power of reputations versus situational labels in determining prisoner's dilemma game moves", Personality and Social Psychology Bulletin, Vol. 30 No. 9, pp. 1175-1185.

Lo, A.W. (2005), "Reconciling efficient markets with behavioral finance: the adaptive markets hypothesis", The Journal of Investment Consulting, Vol. 7 No. 2, pp. 21-44.

Lusk, J.L. and Norwood, F.B. (2010), "Direct versus indirect questioning: an application to the wellbeing of farm animals", Social Indicators Research, Vol. 96 No. 3, pp. 551-565.

Menapace, L., Colson, G. and Raffaelli, R. (2016), "A comparison of hypothetical risk attitude elicitation instruments for explaining farmer crop insurance purchases”, European Review of Agricultural Economics, Vol. 43, pp. 113-135.

Nerlove, M. and Bessler, D.A. (2001), "Expectations, information and dynamics", in Gardner, B. and Rausser, G. (Eds), Handbook of Agricultural Economics, Elsevier, Amsterdam, New York, NY, pp. 155-206.

Ochs, J. (1998), “Coordination in market entry games”, in Budescu, D.V., Erev, I. and Zwick, R. (Eds), Games and Human Behavior, Lawrence Erlbaum Associates, Mahwah, New Jersey, NJ, pp. 143-172.

Ollila, P. (1994), "Farmers' cooperatives as market coordinating institutions", Annals of Public and Cooperative Economics, Vol. 65 No. 1, pp. 81-102.

Rapoport, A. (1995), "Individual strategies in a market-entry game", Group Decision and Negotiation, Vol. 4, pp. 117-133.

Rapoport, A., Seale, D.A., Erev, I. and Sundali, J.A. (1998), "Equilibrium play in large group market entry games", Management Science, Vol. 44 No. 1, pp. 119-141.

Roe, B.E. and Just, D.R. (2009), "Internal and external validity in economics research: tradeoffs between experiments, field experiments, natural experiments, and field data", American Journal of Agricultural Economics, Vol. 91 No. 5, pp. 1266-1271.

Rommel, J., Hermann, D., Müller, M. and Mußhoff, O. (2017), "Comprehension in risk elicitation experiments”, Applied Economics Letters, Vol. 24 No. 9, pp. 627-634.

Rommel, J., Hermann, D., Müller, M. and Musshoff, O. (2019), "Contextual framing and monetary incentives in field experiments on risk preferences: evidence from German farmers", Journal of Agricultural Economics, Vol. 70 No. 2, pp. 408-425.

Savikhin, A.C. and Sheremeta, R.M. (2013), "Simultaneous decision-making in competitive and cooperative environments", Economic Inquiry, Vol. 51 No. 2, pp. 1311-1323.

Schotter, A. and Trevino, I. (2014), "Belief elicitation in the laboratory", Annual Review of Economics, Vol. 6, pp. 103-128.

Seale, D.A. and Rapoport, A. (2000), "Elicitation of strategy profiles in large group coordination games", Experimental Economics, Vol. 3, pp. 153-179.

Smith, V.L. (1976), "Experimental economics: induced value theory", The American Economic Review, Vol. 66 No. 2, pp. 274-279.

Sundali, J.A., Rapoport, A. and Seale, D.A. (1995), "Coordination in market entry games with symmetric players", Organizational Behavior and Human Decision Processes, Vol. 64, pp. 203-218.

Thoyer, S. and Préget, R. (2019), "Enriching the CAP evaluation toolbox with experimental approaches: introduction to the special issue", European Review of Agricultural Economics, Vol. 46 No. 3, pp. 347-366.

Tufano, F. (2010), "Are 'true' preferences revealed in repeated markets? An experimental demonstration of context-dependent valuations", Experimental Economics, Vol. 13 No. 1, pp. 1-13.

Van den Bosch, F., Oliver, R., Van den Berg, F. and Paveley, N. (2014), "Governing principles can guide fungicide-resistance management tactics", Annual Review of Pyhtopathology, Vol. 52, pp. 175-195. 
Weber, E.U., Blais, A.R. and Betz, N.E. (2002), "A domain-specific risk-attitude scale: measuring risk perceptions and risk behaviors", Journal of Behavioral Decision Making, Vol. 15, pp. 263-290.

Zhou, W. and Hey, J. (2018), “Context matters", Experimental Economics, Vol. 21 No. 4, pp. 1-34.

Zwick, R. and Rapoport, A. (2002), "Tacit coordination in a decentralized market entry game with fixed capacity", Experimental Economics, Vol. 5, pp. 253-272.
Simultaneous production decisions 


\section{BFJ 123,13 \\ Appendices Appendix 1.}

34

Table A1. Instructions: Front side (translation, example wheat)
Dear farmers,

Welcome to our decision experiment.

The experiment is about the choice of the wheat variety. In particular, our experiment concerns the cultivation of different quality groups.

The experiment consists of two parts. On the back of this sheet you will find the first part. First you will be asked to make a decision between two alternatives. After you have completed this part, you will be given a questionnaire.

The experiment takes about 10 minutes and you can earn up to $€ 60$.
Imagine selecting wheat varieties for the coming year. You can choose between wheat of quality groups $A$ ( $A$ wheat) and $B$ (B wheat). In both cases, production costs amount to $€ 1,180$.

The other farmers - the other 29 participants in the experiment - are facing this decision. You have two alternatives to choose from:

B wheat

- Has a safe yield of 8.3 tons/hectare and a guaranteed price of $€ 147$ / ton.

- This results in a revenue of $€ 1,220$ ( 8.3 tons $\times € 147$ ).

- After deduction of the production costs $(1,180 €)$ there remains a profit of $40 €$.

A wheat

- Has a safe yield of 8 tons/hectare.

- Depending on the market situation, the price of $A$ wheat varies. There are two cases:

If $20 \%$ or more farmers grow A wheat, there is a high supply. In this case, the price is $150 € /$ ton. This results in a revenue of $€ 1,200$ (8 tons $x € 150$ ). After deducting the costs $(1,180 €$ ), a profit of $20 €$ remains.

or

If less than $20 \%$ of the farmers cultivate $A$ wheat, there is a small supply of $A$ wheat. In this case, the price is $155 € /$ ton. This results in a revenue of $€ 1,240$ ( 8 tons $\times € 155$ ). After deduction of the costs, a profit of $60 €$ remains.

The described yields and the desired qualities are certainly achieved and consequently, there is no uncertainty with regard to these two parameters.

From all participants, $20 \%$ will be drawn, which receive the profit according to their selection The winners will be determined after the second part of the survey.

What do you choose?

B wheat $\square \quad$ A wheat $\square$

Table A2.

Instructions: Example wheat, $20 \%$ (translation) $^{1}$

\footnotetext{
${ }^{1}:$ The $80 \%$ treatment differs from this treatment only in the fact that $80 \%$ appears instead of $20 \%$
} 


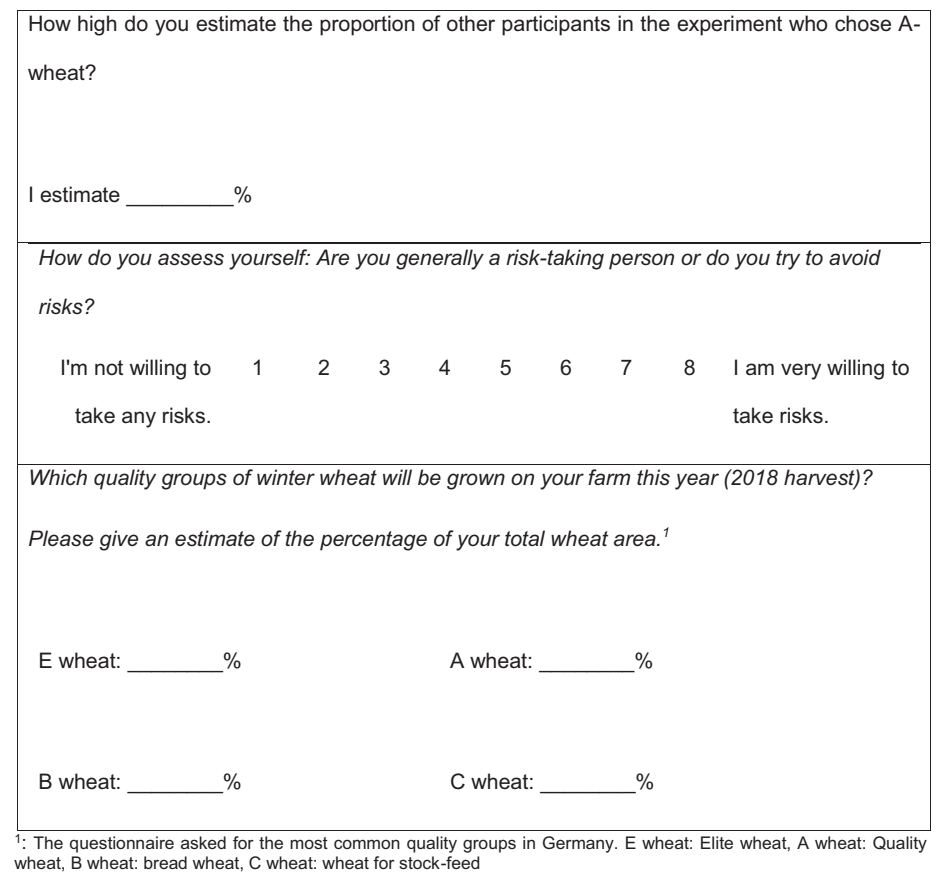

Simultaneous production decisions

Table A3.

Questionnaire (example wheat)

\begin{tabular}{llccrc}
\hline Variable & Context $^{1}$ & $N$ & Mean & SD & Population $^{2}$ \\
\hline Age & All & 300 & 46.51 & 0.798 & $-{ }^{4}$ \\
Gender & All & 319 & $3.4 \%$ Female & & $-{ }^{5}$ \\
Number of sows & Meat & 67 & 108.67 & 27.577 & 171 \\
Number of piglets & Meat & 67 & 438.33 & 115.013 & $451^{3}$ \\
Number of fattening pigs & Meat & 67 & 657.99 & 102.199 & \\
Area in hectares & Wheat, Fungicides & 89 & 139.94 & 21.039 & 66.3
\end{tabular}

Note(s): ${ }^{1}$ : Some variables were only queried in some contexts. ${ }^{2}$ : Federal Ministry of Food and Agriculture (2020), ${ }^{3}:$ In federal statistics summarized as "Other pigs", ${ }^{4}$ : Not available; Federal statistics contain only age groups, ${ }^{5}$ : Not available; Federal statistics contain no information on gender

Table A4. Descriptive statistics

\section{Appendix 2.}

The supplementary material is available online for this article.

\section{About the authors}

Julia Höhler works as an assistant professor in the Business Economics Group, Wageningen University. She is interested in experimental research on cooperation, decision-making, and behavioral economics. Current research topics comprise strategic management, consumer behavior and business management. Julia Höhler is the corresponding author and can be contacted at: julia.hoehler@wur.nl 
BFJ

123,13

Jörg Müller works as a postdoc in the Institute of Farm and Agribusiness Management, Justus Liebig University Giessen (Germany). He is interested in experimental research on decision-making and behavioral economics. Current research topics comprise production decisions, farm management and nudging in agriculture.

For instructions on how to order reprints of this article, please visit our website: www.emeraldgrouppublishing.com/licensing/reprints.htm Or contact us for further details: permissions@emeraldinsight.com 